\title{
Genetical Aspects of Severe Visual Impairment in Childhood
}

\author{
G. R. FRASER*
}

A quantitative assessment of the spectrum of genetically determined diseases which cause severe impairment of vision in childhood is no easy matter. First, apart from the exceptional cases where vision is lost altogether, there are, of course, no universally acceptable criteria whereby 'severe impairment' may be defined. Secondly, this spectrum may be quite significantly affected by the results of treatment. At the qualitative level, however, the situation is less difficult and, in this presentation, clinical entities which often give rise to severe impairment of vision in childhood will be considered in turn together with an attempt to assess the role of genetical factors in their causation.

This is followed by a section in which an attempt is made to give an over-all view, necessarily approximate in view of the difficulties mentioned above, of the relative numerical contributions of these various entities determined by simple Mendelian inheritance to the causation of severe visual impairment in childhood, and in two final sections, the possible roles of polygenic inheritance and of gross chromosomal aberrations are discussed.

\section{Choroido-retinal Degenerations}

This group of conditions, comprehensively described by Franceschetti et al. (1963), illustrates very well the phenomenon that, when visual imimpairment due to a heterogeneous genetically determined entity is considered, only some components cause severe forms leading to significant childhood handicap. As a general rule, though there are exceptions, it seems that autosomal recessive forms give rise to more severe lesions of earlier onset than autosomal dominant forms and, therefore, the former are almost exclusively represented among children with serious visual impairment. Among these children, the overwhelming majority owe their disability to the condition known as the tapeto-retinal degeneration or congenital

* Address: Division of Medical Genetics, Department of Medicine, University of Washington, Seattle, Washington 98105, U.S.A.

5 amaurosis of Leber, corresponding to the retinal aplasia of Sorsby and Williams (1960). There is some evidence (Sorsby and Williams, 1960; Franceschetti et al., 1963) that autosomal dominant forms may exist but, if so, they must be responsible for only a small minority of cases. In addition, phenocopies may occur, and it is probable that acquired causes acting both in the prenatal and the perinatal period can give rise to a clinical picture indistinguishable from that of the more common genetically determined variety.

Characteristically, this condition is marked by visual failure from earliest infancy. At first no retinal lesions may be visible ophthalmoscopically, and, therefore, such visual failure has often been initially described as 'cerebral' or 'cortical' blindness, while in other cases congenital optic atrophy or congenital nystagmus has been diagnosed. The electroretinogram, however, is always grossly abnormal in the earliest stages, and in later years ophthalmoscopically observable lesions often develop, and may progress so that the final picture is not unlike that seen in retinitis pigmentosa. Cataracts and keratoconus are common late complications of the condition.

It is probable (Fraser and Friedmann, 1967) that Leber's congenital amaurosis, like autosomal recessive deafness, may be determined by homozygosity for an abnormal allele at any one of several gene loci. Thus, the same phenomenon occurs as in the case of autosomal recessive deafness that persons affected with Leber's congenital amaurosis who marry may often have normal children (Waardenburg and Schappert-Kimmijser, 1963). There are some suggestions (Fraser and Friedmann, 1967) of ophthalmoscopically definable variations in the appearances of the fundus which may correspond to different genetical forms of the condition. Some component entities of this group may be distinguished by associated clinical features such as the syndrome of Leber's congenital amaurosis with renal abnormalities (Contreras and Espinoza, 1960; Senior, Friedmann, and Braudo, 1961; Loken et al., 
1961; Fraser and Friedmann, 1967); concomitant neurological abnormalities, possibly including deafness, may distinguish other variants (Franceschetti et al., 1963; Dekaban and Carr, 1966; Fraser and Friedmann, 1967).

Apart from the group of conditions of the type of Leber's congenital amaurosis, blindness of later onset in childhood may be caused by autosomal recessive choroido-retinal degenerations due to homozygosity at other gene loci. These dystrophies involve primarily the macula, but the periphery of the retina may participate in the degenerative process. Thus, the group includes such entities as Stargardt's macular dystrophy and 'central' retinitis pigmentosa; as in the case of Leber's tapeto-retinal degeneration, homozygosity at one of several gene loci may be involved. Some entities within this group may be distinguished by associated clinical features such as the various forms of amaurotic idiocy, or cerebromacular degeneration, and other less clearly defined associations of choroido-retinal degenerations with neurological disorders. In addition, there are probably several distinct forms of autosomal dominant choroido-retinal degenerations involving the macula, but, in general, these do not cause severe visual impairment in childhood. It is probable that phenocopies of this group of choroido-retinal degenerations with onset in infancy and childhood may occasionally arise due to viral infections. In such cases, a typical history may be elicited of sudden onset of visual symptoms during or shortly after an episode of high fever commonly associated with an exanthematous eruption.

It should be noted that in the usual forms of retinitis pigmentosa, both autosomal dominant and autosomal recessive, the lesions are primarily peripheral. Thus, the macula is relatively spared and central vision may be preserved till an advanced age. These conditions, therefore, which include Usher's syndrome (autosomal recessive deafness with retinitis pigmentosa), only very rarely cause severe visual impairment in childhood.

Another autosomal recessive condition that may cause serious visual handicap in infancy and childhood is albinism. This, too, is a genetically heterogeneous condition, and, as the families described by TrevorRoper (1952) and Witkop et al. (1970) show, the marriage of albinos may lead to normal offspring. Two gene defects at different loci may correspond to the clinical distinction between complete (or universal) and incomplete albinism, and there is evidence that this difference may be distinguishable at the biochemical level also (Witkop et al., 1970). In addition, homozygosity at further gene loci gives rise to the Chédiak-Higashi syndrome of albinism with defects of leucocyte function usually leading to early death through infection, and to the syndrome $\stackrel{\mathbb{D}}{\overparen{D}}$ of Heřmanský and Pudlák (1959) in which albinism is associated with a bleeding diathesis of an indeterminate nature.

Sex-linked choroido-retinal degenerations may also cause severe visual impairment in males. They include ocular albinism, choroideraemia, and a group of retinal dystrophies clinically allied to $\varnothing$ retinitis pigmentosa. In such cases, diagnosis is के greatly assisted by minor ophthalmoscopic changes $\overrightarrow{0}$ commonly found in heterozygotes. This phenomenon provides one of the main lines of evidence bearing on the existence and the nature of $\mathrm{X}$ chromosomal inactivation (Lyon, 1961) in man.

\section{Retinoblastoma}

One of the most common autosomal dominant causes of blindness in childhood is bilateral retinoblastoma. Discovery of the genetical determination of retinoblastoma became possible only when surgical treatment ensured the survival of a substantial proportion of affected subjects to reproductive age. It was then soon noted that the condition could be handed on from parent to offspring in a Mendelian dominant manner. However, the studies of Vogel (1957) first clearly showed that this explanation could not apply to all cases, in that the proportion of affected children of affected subjects was very much less than the $50 \%$ expected under the hypothesis of dominant inheritance. Vogel (1957) suggested that the majority (perhaps as much as $80 \%$ ) of cases of unilateral sporadic retinoblastoma represented phenocopies, possibly due to somatic mutation, and, therefore, in such cases the disease is not transmissible to offspring of affected persons, whereas bilateral retinoblastoma usually, if not invariably, represents the results of a germinal and, therefore, transmissible mutation. This hypothesis was confirmed in the case of bilateral retinoblastoma by the work of Hemmes, Nijland, and SchappertKimmijser (1964) who studied 7 persons with sporadic bilateral retinoblastoma who survived to procreate; they had 22 children of whom 12 were themselves affected, in good accord with the $50 \%$ expected under the hypothesis that all cases of bilateral tumour represent germinal and transmissible mutations.

In a condition such as bilateral retinoblastoma, which until relatively recently was almost invariably fatal in early life, it is to be expected that a large proportion of sporadic genetically determined cases will be caused by freshly arisen mutations. Not all such cases, however, are due to this mechanism, 
since there is considerable evidence of reduced penetrance of the gene concerned, so that sometimes such sporadic cases will arise because of transmission of the abnormal gene from a parent in whom it has not caused disease. Perhaps a realistic estimate of the clinical penetrance of the gene would be $80 \%$, and thus, occasionally, an unaffected carrier may have more than one affected child; in this way autosomal recessive inheritance may be simulated.

A particularly fascinating phenomenon is spontaneous regression of retinoblastoma which has been documented relatively frequently in members of families who have been under close observation because of the presence of the disease in relatives, but who have not undergone treatment (Steward, Smith, and Arnold, 1956; Watillon et al., 1964; Fraser and Friedmann, 1967). It is clear that intensive study of the mechanism of spontaneous regression of retinoblastoma, and of malignant tumours in general, could lead to the development of revolutionary therapeutic techniques in the field of cancer, based on attempts to simulate these natural cures.

\section{Pseudoglioma}

Pseudoglioma, as its name implies, is any condition of the eye which simulates retinoblastoma. It may be unilateral or bilateral and it is the latter variety that is of primary concern here. It may be due to acquired causes such as retrolental fibroplasia, congenital toxoplasmosis, Coats' disease, or metastatic endophthalmitis. If such causes can be confidently excluded, a large proportion of residual cases is genetically determined, most commonly in a sex-linked recessive manner. Occasionally, however, autosomal recessive types of pseudoglioma may occur. Detachment of the retina forms part of the pathological picture of pseudoglioma; it is in most cases congenital, but it may occur in early postnatal life. As a result of such differences in the timing and extent of the primary lesion, the condition in question (sometimes known as Norrie's disease) can masquerade under a variety of diagnoses including persistent hyperplastic primary vitreous, congenital retinal fold, congenital falciform retinal detachment, congenital (or infantile) cystic retinal detachment, congenital vascular veils in the vitreous, and juvenile retinoschisis. This multitude of clinical diagnoses may indicate heterogeneity at the clinical level also. The retinal detachment is followed by disorganization of the eye of varying degree, and, when the extent of this process is particularly obvious and its progress particularly rapid, microphthalmos with cataracts may be simu- lated, the end stage in such cases being phthisis bulbi.

An extensive description of pseudoglioma (or Norrie's disease) has been published by Warburg (1966), with a report of many Scandinavian families with this condition. Mental subnormality and perceptive deafness, with onset in middle childhood and later, are relatively frequent accompaniments of the condition.

\section{Optic Atrophy}

Genetically determined optic atrophy giving rise to serious visual disability in childhood often forms part of complex neurological syndromes such as spastic paraplegias, hereditary ataxias, Behr's complicated optic atrophy, cerebral lipidoses, or leucodystrophies. 'Simple' types without an associated widespread involvement of the central nervous system may also occur. Complex types are sometimes associated with retinal involvement and are often inherited in an autosomal recessive manner, though dominant forms may occasionally be seen. One particularly interesting form of autosomal recessive complex optic atrophy is that associated with juvenile diabetes mellitus (Rose et al., 1966). While the neurological disturbance in this condition is often restricted to optic atrophy, other cases may show features such as retinal degeneration, mild perceptive deafness, ataxia, and myelopathy; in addition, abnormalities of the electroencephalogram, air encephalogram, and cerebrospinal fluid protein level may occur, suggesting the existence of a more diffuse involvement of the central nervous system. Another frequent concomitant feature of this syndrome or group of syndromes is diabetes insipidus.

Autosomal recessive inheritance is very rare in 'simple' optic atrophy (Kjer, 1959), and some cases described under this heading may in fact represent examples of Leber's congenital amaurosis or retinal aplasia. Autosomal dominant inheritance of 'simple' forms is undoubtedly far more common. Anomalous inheritance patterns are found in Leber's optic atrophy; in view of the demonstration by Bruyn and Went (1964) of widespread neurological disturbances in some such cases, it is not clear whether this condition should be regarded as a 'simple' or 'complex' type of optic atrophy. It only rarely causes severe visual handicap in childhood and then exclusively in males. More typically, the onset of significant symptoms is deferred till adolescence or adult life, and the disease is far less severe in females. Provisionally the condition may be best regarded as inherited in a sex-linked manner with very variable manifestations in female heterozygotes. There are two major difficulties 
which indicate that such a simple explanation is not entirely adequate. One is that the disease has never been transmitted by an affected male-that is from grandfather to grandson through a heterozygous female-and the second is that the proportion of daughters of heterozygotes who are themselves carriers is far greater than the $50 \%$ expected.

Apart from the specific conditions mentioned above, optic atrophy as a cause of severe visual handicap in childhood is often found in association with evidence of brain damage such as epilepsy, cerebral palsy, neurological defect, mental subnormality, and deafness. Such cases frequently occur in premature children and are in all probability not genetically determined; they are usually associated with evidence of traumatic episodes in the perinatal period. The whole complex has, therefore, been tentatively designated as the 'perinatal damage syndrome' by Fraser and Friedmann (1967); males are more often affected than females. Occasionally difficulty may arise in distinguishing between conditions in this category and genetically determined complex neurological syndromes such as Behr's complicated optic atrophy.

\section{Cataracts}

Apart from bilateral retinoblastoma, cataracts constitute the other common autosomal dominant lesion causing severe visual handicap in childhood. Since retinoblastoma is potentially lethal as well as usually giving rise to total blindness, it reduces fitness far more than cataracts which are not only fully compatible with a normal life expectancy but also often lead to visual handicap of only moderate severity. Thus, a far smaller proportion of cases of cataracts than of retinoblastoma represents freshly arisen mutations, and a family history characteristic of dominant inheritance is much more common. Nevertheless, there always remains a possibility that a sporadic case may be due to a freshly arisen mutation. Autosomal recessive congenital and infantile cataracts do occur but are much more rare than the autosomal dominant variety; occasional pedigrees have been reported which are suggestive of sex-linked intermediate inheritance (Walsh and Wegman, 1937; Fraccaro et al., 1967; Fraser and Friedmann, 1967).

In several of the recessive forms a metabolic abnormality has been identified, and these include galactosaemia, galactokinase deficiency (Gitzelmann, 1967), and a form of glycogen storage disorder (De Loore and Van Gelderen, 1967). Cataracts may be associated with hyperaminoaciduria in the oculocerebro-renal syndrome of Lowe, Terrey, and MacLachlan (1952), which is a sex-linked recessive condition; and various investigators have suggested that deficiency of glucose-6-phosphate-dehydrogenase, another sex-linked recessive error of metabolism, may be associated with cataracts in early life, but the evidence is not convincing [see Fraser and Friedmann (1967) for references].

Further autosomal recessive types of cataract may be distinguished by their association with other clinical features as part of various syndromes. These include the Marionesco-Sjögren syndrome, the Rothmund-Thomson syndrome, the Werner syndrome, the association of cataracts with congenital ichthyosis (Jancke, 1950; Pinkerton, 1958), with renal tubular necrosis, dwarfism, mental retardation, and epilepsy (Crome, Duckett, and Franklin, 1963), and with various other less clearly defined constellations of neurological abnormalities such as progressive cerebral diplegia or congenital choreoathetosis. It should be emphasized that the time of onset of cataract in many of these syndromes is very variable. Thus, it may often cause visual impairment only in adolescence or adult life. Such later development of cataract is also a common complication of several autosomal recessive choroido-retinal degenerations, including both those of the type of Leber's congenital amaurosis and of the type of retinitis pigmentosa.

As in the case of optic atrophy, there is a good deal of evidence (Fraser and Friedmann, 1967) that unfavourable events of an unidentified nature in pre- or perinatal life, occurring predominantly in premature children, give rise to cataracts in association with other symptoms characteristic of brain damage; the possibility has been raised by several investigators that this syndrome may be associated with idiopathic neonatal or infantile hypoglycaemia (O'Connor and Crawford, 1967; Fraser and Friedmann, 1967; Hull, 1969; Gabilan and Chaussain, 1969). As in the case of the 'perinatal damage syndrome' involving optic trophy (mentioned above) males are affected more frequently than females. There is, in addition, a well-known connexion between cataracts and maternal rubella infection. Cataracts due to such primarily acquired causes may be confused with genetically determined varieties.

Schemes of classification of genetically determined cataracts based on morphological patterns of lens involvement have been proposed, for example by François (1959). The correspondence between forms defined by such criteria and distinct genetical entities is limited, and such schemes are not particularly relevant to the congenital and infantile severe types under discussion since these cataracts are very often total. Involvement of affected relatives of dominant cases is very variable, however, 
and many have only mild visual impairment. Other factors apart from the cataract are involved in the prognosis for vision, notably the degree of microphthalmos. Thus, when the eye is very small, vision is reduced to a greater extent and the results of surgery are less successful.

\section{Myopia}

Uncomplicated high myopia may occasionally be of sufficient severity to cause serious visual handicap in childhood. Dominant forms are known but these usually cause blindness through associated retinal detachment. A very well-defined entity is that of sex-linked recessive congenital myopia with nystagmus and night blindness (Nettleship, 1912).

Autosomal recessive forms of high myopia have been described but the evidence is not entirely convincing. Sufficiently severe myopia to cause serious childhood handicap may sometimes represent the extreme of the normal 'physiological' refraction curve, and presumably in such cases it is under the control of polygenic inheritance. Lastly, prematurity predisposes to an acquired form of high myopia; some such cases may represent abortive forms of retrolental fibroplasia.

\section{Retinal Detachment}

Retinal detachment in childhood is usually a complication of high myopia, and the combination is often inherited in an autosomal dominant manner. In addition, there are instances of autosomal dominant, autosomal recessive, and sex-linked recessive types of retinal detachment in early life, which are not associated with high myopia; such a lesion may readily be classified as a pseudoglioma. Indeed, the diagnostic label applied may reflect only differences in a spectrum of continuous variation involving the timing and extent of the retinal detachment, though it remains quite possible that, to take the sex-linked group as an example, lesions of the pseudoglioma group and those defined as juvenile retinal detachment or retinoschisis represent distinct genetical entities.

\section{Corneal Lesions}

Both autosomal dominant and autosomal recessive types of corneal dystrophies are known and, as in the case of cataract, may tentatively be classified according to morphological patterns of involvement of the cornea. They are relatively common but rarely cause severe impairment of vision in childhood. Great care must be taken to exclude acquired causation in an individual case. Thus, congenital syphilis was formerly an important cause of keratitis in infancy and childhood, and other prenatally acquired causes may be of significance (Speakman and Crawford, 1966). Infection may also leave keratitis as a sequel.

\section{Coloboma-Microphthalmos- Anophthalmos}

Microphthalmos, per se, may be a feature of a great number of different entities both genetical, such as dominant cataract and sex-linked pseudoglioma, described in other sections, and acquired, such as toxoplasmosis and retrolental fibroplasia. Other genetically determined forms may be associated with myopia and corectopia (Usher, 1921) and with retinitis pigmentosa (Hermann, 1958) in autosomal dominant syndromes, and with macrophakia, hypermetropia, retinal degeneration, and dental anomalies in an autosomal recessive syndrome (Franceschetti and Gernet, 1965).

In addition, an association seems to exist between colobomatous defects of the eye and microphthalmos which in its extreme form ranges into anophthalmos. Irregular dominant inheritance is characteristic of this group of defects. Thus, only a proportion of persons of the appropriate genotype will be severely affected in both eyes while minor abnormalities, often unilateral, will occur in others. Sometimes inheritance will be apparently recessive but this may be an artefact due to lack of penetrance of the gene in previous generations. Possibly, truly recessive types of anophthalmos may occur, but such families may reflect homozygosis for genes which in heterozygous form cause milder forms of this group of lesions (Sorsby, 1934; van Canneyt and Vandemeulebroecke, 1936).

\section{Aniridia}

Like microphthalmos, aniridia can also be associated with colobomatous lesions either in the same individual or in other members of the family. It usually follows a regular pattern of dominant inheritance, but variable expressivity does occur and apparent examples of 'recessive' inheritance may be explicable on the basis of minor manifestations in one of the parents. A rare truly recessive form in association with cerebellar ataxia and mental retardation may, however, exist (Gillespie, 1965). Sporadic cases are probably mostly attributable to freshly arisen mutations.

\section{Buphthalmos}

Buphthalmos or infantile glaucoma is sometimes a secondary manifestation of other ocular abnormalities such as, for example, aniridia. Primary 
buphthalmos, on the other hand, presents a considerable problem of nosological delineation. Autosomal recessive types undoubtedly occur, as shown by the involvement of multiple sibs and by an increase of parental consanguinity. In a few cases, dominant inheritance seems likely and, in addition, buphthalmos may occasionally be identified as a component of Lowe's oculo-cerebro-renal syndrome which is inherited in a sex-linked recessive manner. In this context, Franceschetti (1961) found evidence of hyperaminoaciduria in 22 of 44 males and 6 of 19 females with buphthalmos, and suggested the existence of oculo-renal disturbances of a wide range of severity, possibly related to Lowe's syndrome.

Fraser and Friedmann (1967), however, came to the conclusion that these single gene patterns of inheritance could account only for a minority of cases, since most are non-familial and there is a large excess of males in all reported series which cannot be explained solely in terms of the small proportion due to sex-linked inheritance. They postulated, therefore, that more complicated polygenic mechanisms of inheritance were operative in the majority of cases. Under this hypothesis, such multiple genetical factors, perhaps interacting with others determined environmentally, might be thought of as resulting in deviations from normal embryogenesis of the eye structures giving rise to malformations which, in common with many lesions with this type of causation, show a strong association with sex, boys being affected much more frequently than girls in this case.

\section{Severe Visual Impairment in Childhood as One Component of Complex Syndromes Determined by Single Gene Inheritance}

In the main, the effects of the pathological conditions discussed above have been confined to the visual apparatus though sometimes other portions of the central nervous system have been involved. Many additional syndromes exist which are inherited in a simple Mendelian manner and in which the eye is involved in conjunction with other organ systems.

Thus, severe visual impairment in childhood may be a feature of many of the generalized disorders of connective tissue comprehensively discussed by McKusick (1966). These include autosomal dominant conditions such as Marfan's syndrome, Ehlers-Danlos syndrome, and osteogenesis imperfecta, and autosomal recessive conditions such as pseudoxanthoma elasticum, homocystinuria, WeillMarchesani syndrome, and some forms of mucopolysaccharidosis. In some of these conditions, eye involvement is of very variable type, and severe visual impairment in childhood is rare (osteogenesis imperfecta, Ehlers-Danlos syndrome, pseudoxanthoma elasticum), while in others the eye $\vec{F}$ manifestations are constant and lead more fre- $\stackrel{\mathcal{O}}{+}$ quently to serious and early visual impairment. Thus, ectopia lentis (often associated with high myopia) and its secondary complications frequently occur in Marfan's syndrome, homocystinuria, and the Weill-Marchesani syndrome, while severe corneal dystrophies are common in mucopolysaccharidoses I (Hurler's syndrome), V (Scheie's syndrome) and VI (Maroteaux-Lamy syndrome). In addition, choroido-retinal degenerations may occur in almost all forms of mucopolysaccharidosis, but severe visual impairment in childhood is always due to the corneal changes.

In addition, generalized genetically determined skeletal disorders exist, in association with which severe visual impairment may occur in childhood, such as autosomal recessive chondrodystrophia calcificans congenita with cataracts (Conradi's syndrome), and myopia and retinal detachment with dysplasia spondyloepiphysaria congenita and, possibly, with other related conditions (Fraser et al., 1969), inherited in an autosomal dominant manner Retinal lesions of the type of retinal aplasia of retinitis pigmentosa occur in association with poly dactyly and the other features of the Laurences Moon-Bardet-Biedl syndrome, with microcephaly (McKusick et al., 1966; Schmidt, Jaeger, and Neubauer, 1967), and with dwarfism and other anomalies in Cockayne's syndrome, all three conditions being inherited in an autosomal recessive manner. Abnormalities of the iris of the type of Rieger's (1934) autosomal dominant mesodermal dysgenesis of the anterior segment may coexist with skeletal and visceral abnormalities.

Microphthalmos, often in association with cataract, may occur in several complex syndromes. Thus, oculo-dento-digital dysplasia is probably an autosomal dominant condition, consisting of microphthalmos in association with small nose, hypotrichosis, dental anomalies, camptodactyly of the fifth fingers, syndactyly, and missing toe phalanges. In addition, Lenz (1955) described a sex-linked recessive form of microphthalmos in association with digital, genital, and other malformations. Congenital cataracts with microphthalmos may also be responsible for severe visual impairment in childhood in the François-Hallermann-Streiff syndrome, involving proportionate dwarfism, lack of head hair, dental maldevelopment, and osseous anomalies of the skull which give rise to a characteristic facial appearance. Autosomal dominant 
inheritance seems likely in this condition, but evidence of direct transmission from parent to child and of familial incidence in general is somewhat equivocal. This may be because of reduced fitness of affected persons, on account of blindness and an unprepossessing appearance, and its consequence that virtually all cases may represent freshly arisen mutations. ${ }^{\star}$ Bueno Sánchez (1966) described a family in which this condition was apparently inherited in an autosomal recessive manner, but an examination of his report reveals that it was based on a misdiagnosis, and the affected sibs certainly did not have the François-Hallermann-Streiff syndrome.

Another syndrome involving cataracts with dental maldevelopment and webbed toes was responsible for visual handicap in 3 of the 776 children studied by Fraser and Friedmann (1967): all 3 were girls. The exact genetical and nosological status of this syndrome is unclear but, like the François-Hallermann-Streiff syndrome, it may be determined by autosomal dominant inheritance, the 3 cases in question representing freshly arisen mutations.

Other malformative syndromes where single gene dominant inheritance may be operative and which many include severe visual impairment in childhood include the Pierre Robin syndrome (Smith, Cavanaugh, and Stowe, 1960), and conditions involving maldevelopment of the eyes and ears together with osseous anomalies of the facial skeleton and vertebrae of the type of the oculovertebral syndrome of Weyers and Thier (1958).

Incontinentia pigmenti may sometimes give rise to severe visual impairment usually due to lesions of the type of pseudoglioma. The mode of inheritance of this condition has not been elucidated but it may best provisionally be regarded as due to a gene on the $\mathrm{X}$ chromosome which gives rise to the disease in heterozygous females (X-linked dominant inheritance) and is usually lethal in early foetal life in males.

Most of the malformative syndromes discussed thus far are inherited in an autosomal dominant manner, but the autosomal recessive cryptophthalmos syndrome forms an exception to this rule which is of particular interest. This comprises an exceedingly complex constellation of malformations involving both the viscera and the skeletal system (Fraser, 1962). The feature which gives the condition its name and which leads to blindness is failure of formation of a division between the eyelids, combined with rudimentary development of the ocular globe. Renal

\footnotetext{
* Circumstantial evidence of the presence of fresh mutation may be afforded by an increase in parental, especially paternal, age at the birth of affected children. While this information is often not recorded, in a recent case report (Ide and Webb, 1969) the paternal age at birth was 61 years and the maternal 33 years.
}

hypoplasia is common and when extreme, as is often the case, is incompatible with postnatal survival. The gene concerned, therefore, is sublethal and the homozygous survivors may be regarded as 'Durchbrenner' in the sense of Hadorn (1955), meaning that they have escaped the lethal effects of the gene by passing a critical threshold in the range of variation of renal development found in this syndrome. A rough and ready rule governing the clinical manifestations of genetically determined conditions seems to be that malformative syndromes are inherited in a dominant manner whereas recessive conditions are often such as to be explicable in terms of deficient action of a single enzyme usually in postnatal life. The cryptophthalmos syndrome and several other complex malformation syndromes form exceptions to this rule, and, in the case of the cryptophthalmos syndrome, Fraser and Friedmann (1967) have adduced evidence that this condition may be due to homozygosis for a gene which in the heterozygous state may be responsible for minor ocular abnormalities such as moderate degrees of microphthalmos and blepharochalasis. $\dagger$

Lastly, severe visual impairment in childhood may occur not as a component of a complex syndrome but as a result, often because of malformations of the skull leading to raised intracranial pressure and optic atrophy. Among conditions of this type determined in a simple Mendelian manner, the following may be mentioned: Crouzon's craniofacial dysostosis, Apert's acrocephalosyndactyly, and other less well-defined forms of craniostenosis and of oxycephaly, all probably inherited in an autosomal dominant manner, autosomal recessive osteopetrosis, and occasional sex-linked recessive cases of hydrocephalus (Fanconi, 1934; Edwards, 1960).

\section{Quantitative Aspects of Conditions Determined by Simple Mendelian Inheritance in Causation of Severe Visual Impairment in Childhood}

Apart from the difficulties mentioned in the introduction that no universally acceptable criteria exist for the definition of severe visual impairment in childhood and that the spectrum of causation is modified by treatment, especially in the case of such conditions as cataract, corneal lesions, and buphthalmos, there are other problems involved in attempting to define the numerical roles of the various

t The possibility cannot of course be excluded that the 'gene' in question represents a small chromosomal rearrangement which is not detectable by currently available microscopical methods; such a defect could readily give rise to Mendelian patterns of inheritance, and perhaps accords better with phenotypes involving this and other multiple malformation syndromes than does a mutation of a single gene. 
entities discussed thus far in the causation of severe visual impairment in childhood. Diagnosis is often difficult and the condition originally responsible for visual loss can frequently not be identified unequivocally. Again, even if diagnosis is possible at the pathological level, the mode of inheritance may not be identifiable in each individual case. Nevertheless, children with severe visual handicap are in many countries segregated in schools or institutions for the ineducable, and surveys such as those of Fraser and Friedmann (1967) or Fontaine et al. (1969) may be used to obtain an approximate idea of the quantitative distribution of these entities determined in a simple Mendelian manner in these populations. Needless to say, this spectrum is likely to vary considerably in different parts of the world, and conclusions drawn from such populations in Western Europe, where most such surveys have been performed, cannot be regarded as universally applicable.

Of all the main subgroups discussed above, choroido-retinal degenerations represent the most common single cause of severe visual impairment in childhood. The vast majority are inherited in an autosomal recessive manner, and homozygosity at one of a number of different gene loci is likely to be involved. Congenital lesions of the type of Leber's amaurosis, or retinal aplasia, are the most frequent but a substantial proportion of cases owe their handicap to choroido-retinal degenerations of later onset involving primarily the macula (Stargardt's macular dystrophy, 'central' retinitis pigmentosa). In a further number, the visual impairment is associated with one of the forms of albinism. A few cases of sex-linked recessive choroido-retinal degenerations may be seen, and very occasionally autosomal dominant inheritance is involved. In all, choroido-retinal degeneration may be responsible for a third or so of all cases of severe visual impairment in childhood due to Mendelian segregation of single genes.

Almost another third is shared approximately equally between cataracts and bilateral retinoblastoma. The vast majority of cataracts are inherited in an autosomal dominant manner, but occasionally recessive forms, both sex-linked and autosomal, are seen and, in such cases, metabolic abnormalities can sometimes be detected.

The other entities discussed above collectively make up the remaining third or so of causes of severe visual impairment in childhood. None is individually very common, but quite a substantial proportion involves the complex syndromes discussed in the previous section.

In all, Mendelian segregation of single genes may be responsible for almost a half of all cases of severe visual impairment in childhood, though the proportion may be somewhat less among ineducable $\stackrel{\mathbb{D}}{\stackrel{4}{+}}$ children in whom acquired causes probably play a $\vec{F}$ larger role. It is notable that, whereas in other $\stackrel{5}{+}$ common forms of childhood handicap due to segregation of single genes, such as deafness, mental retardation, or cerebral palsy, autosomal recessive inheritance plays by far the major role, in the case $\triangle$ of visual impairment autosomal dominant in- के heritance is as important if not more so. This may $\overrightarrow{0}$ be due, in part at least, to the fact that dominant conditions do not cause such severe restrictions of $\vec{\omega}$ fertility in the case of visual impairment as in the case of these other forms of childhood handicap. Thus, dominant cataracts often lead only to moderate visual loss, and retinoblastoma, previously almost invariably fatal in infancy, is now frequently compatible with reproduction. Whatever the cause of this frequent occurrence of autosomal dominant inheritance in the case of severe visual impairment in childhood, it is of considerable importance from the point of genetical counselling, since, as a consequence, such impairment may relatively often be transmitted from parent to offspring.

\section{Severe Visual Impairment in Childhood due to Polygenic Inheritance and to Interactions Between Multiple Genetical and Environmental Factors}

Severe visual impairment in childhood may be due in as much as $50 \%$ of cases to primarily acquired causes, though this proportion is decreasing rapidly as children with retrolental fibroplasia reach adult life. The qualification 'primarily' is used advisedly since, of course, in virtually all cases, genetical factors, probably of a complex nature, interact with environmental factors to produce the visual damage. Thus, cataracts due to maternal rubella in pregnancy are the most common cause of prenatally acquired severe visual impairment in childhood; clearly, however, the genotype both of the mother and of the foetus interact with exposure to the virus in determining the extent of foetal involvement.

Again, severe visual impairment in childhood is very often due to primarily acquired causes acting in the perinatal period which may give rise to retrolental fibroplasia, cataracts, optic atrophy, and probably, in occasional cases, myopia, buphthalmos, and choroido-retinal degenerations. Not only is the genotype of the child, in general, important in determining his susceptibility to the effect of noxious environmental influences in this critical perinatal period, but also such disastrous 
results occur predominantly in premature children and, ipso facto, in twins; in this way, the complex genetical bases of prematurity and of twinning are involved.

Lastly, causes acting in infancy and childhood involve mainly infectious and autoimmune diseases, and cerebral tumours. In each case, complex genetical factors play a role in aetiology, by determining susceptibility to infectious disease, the onset and extent of autoimmune damage, and the predisposition to malignant neoplasia.

Apart from these primarily acquired causes, it is probable that, in a substantial number of cases (perhaps as much as $5-10 \%$ ), severe visual impairment in childhood is due primarily to polygenic inheritance, that is to say to the synergistic action of a large number of genes, each with a small individual effect but collectively giving rise to an extreme disturbance of eye structure causing severe visual impairment. This type of inheritance is familiar in the case of intelligence or height; it is a no less probable mechanism in the determination of the parameters of shape and size of the eye, extreme 'physiological' variation in these parameters giving rise to high degrees of myopia. A refinement of the theory of polygenic inheritance involves a 'threshold' effect which implies that when the deviation from average population values determined by multiple genes, each with a small effect, reaches a certain level, some process essential to normal development can no longer take place. Such a mechanism may control the relation between skull width and palatal closure and, by the same token, disturbances of the normal anatomical relationships of the eye leading to such lesions as coloboma and buphthalmos.

Apart from such 'simple' forms of high myopia, coloboma, and buphthalmos tentatively ascribed to these mechanisms, they may also be operative in the causation of various complex conditions such as the Sturge-Weber syndrome and various other illdefined associations of eye defects with involvement of other organ systems, especially the skeleton. In addition, severe visual impairment may be due to optic atrophy as a secondary result of malformations, presumably determined in this way, which are associated with increases of intracranial pressure such as hydrocephalus, meningocele, and encephalocele.

\section{Severe Visual Impairment in Association with Gross Anomalies of Karyotype}

Serious ocular involvement is extremely common in known syndromes due to chromosomal aberrations involving the autosomes, though much less frequent in persons with abnormalities of the sex chromosomes (François, 1967; François, Matton-van Leuven, and Gombault 1970). Thus, in conditions due to trisomy of the $D$ and $E$ chromosomes gross morphological maldevelopment of the eyes is frequently seen, but such children rarely survive more than a few days and, therefore, do not make a significant contribution to severe visual handicap in childhood. The association of Down's syndrome or G group trisomy with cataracts is well known.

In addition to conditions that are associated with aberrations involving entire chromosomes, specific associations of eye defects with less severe chromosomal anomalies have been described. Thus, for example, Schachenmann et al. (1965) described a syndrome consisting of coloboma of the iris, anal stenosis, and renal malformation in association with a small additional acrocentric chromosomal fragment, this anomaly being inherited as an autosomal dominant condition. It is interesting to note that anal stenosis may be seen in association with Rieger's mesodermal dysgenesis of the anterior segment (Brailey, 1890; Crawford, 1967), so that anomalies of the iris coexist with anal stenosis in two autosomal dominant syndromes, one associated with a visible chromosomal anomaly and the other not.

Allderdice et al. (1969) have suggested that deletion of part of the long arm of a D chromosome, probably 13, gives rise to a characteristic clinical syndrome, with facial dystrophy, psychomotor retardation, and absent or hypoplastic thumbs, which often also involves the eyes in that retinoblastoma, microphthalmos, and coloboma of the iris may occur.

Fraser et al. (1970) have reported karyotype studies in families of 23 of the 776 children with severe visual handicap studied by Fraser and Friedmann (1967). These children were selected for karyotype study because of unusual constellations of congenital defects in association with their visual handicap, or because of anomalous hereditary patterns of the primary ocular lesion. No abnormal karyotypes were found. It should be emphasized, however, that all of the children studied by Fraser and Friedmann (1967) attended schools or training centres and none was so mentally subnormal as to be regarded as entirely ineducable. Thus, in view of the virtually constant association of gross mental subnormality with major chromosomal aberrations, the absence of abnormal findings in this group is not unexpected. The situation may well be different among children selected both through visual handicap and mental subnormality.

Support from Public Health Service Grant GM15253 during the preparation of this paper is gratefully acknowledged. 


\section{REFERENCES}

Allderdice, P. W., Davis, J. G., Miller, O. J., Klinger, H. P., Warburton, D., Miller, D. A., Allen, F. H., Jr., Abrams, C. A. L., and McGilvray, E. (1969). The 13q- deletion syndrome. American fournal of Human Genetics, 21, 499-512.

Brailey, W. A. (1890). Double microphthalmos with defective development of iris, teeth and anus. Glaucoma at an early age. Transactions of the Ophthalmological Society of the United Kingdom, 10, 139-140.

Bruyn, G. W., and Went, L. N. (1964). A sex-linked heredodegenerative neurological disorder, associated with Leber's optic atrophy. I. Clinical studies. Fournal of the Neurological Sciences, 1, 59-80.

Bueno Sánchez, M. (1966). Síndrome de Hallerman-StreiffFrançois. A propósito de una presentación familiar. Boletín de la Sociedad Vasco-Navarra de Pediatria, 1, 21-35.

Contreras, B. C., and Espinoza, S. J. (1960). Discusión clinica y anatomopatologica de enfermos que presentaron un problema diagnostico. Pediatria (Santiago), 3, 271.

Crawford, R. A. D. (1967). Iris dysgenesis with other anomalies. British fournal of Ophthalmology, 51, 438-440.

Crome, L., Duckett, S., and Franklin, A. W. (1963). Congenital cataracts, renal tubular necrosis and encephalopathy in two sisters. Archives of Disease in Childhood, 38, 505-515.

De Loore, I., and Van Gelderen, H. H. (1967). Liver glycogenosis and cataracts in a mentally deficient child. Archives of Disease in Childhood, 42, 435-440.

Dekaban, A., and Carr, R. (1966). Congenital amaurosis of retinal origin. Frequent association with neurological disorders. Archives of Neurology, 14, 294-301.

Edwards, J. H. (1960). The syndrome of sex-linked hydrocephalus. Archives of Disease in Childhood, 36, 486-493.

Fanconi, G. (1934). Zur Diagnose und Therapie hydrocephalischer und verwandter Zustände. Schweizerische medizinische Wochenschrift, 64, 214-223.

Fontaine, M., Aron, J.-J., Perdriel, G., and Rousselie, F. (1969). Les Cécités de l'Enfance. Masson, Paris.

Fraccaro, M., Morone, G., Manfredini, U., and Sanger, R. (1967). X-linked cataract. Annals of Human Genetics, 31, 45-50.

Franceschetti, A. (1961). Aminoacidurie dans la cataracte et le glaucome d'origine congénitale. Analogies avec le syndrome oculo-cérébro-rénal de Lowe-Terrey-MacLachlan. Bulletin der Schweizerischen Akademie der medizinischen Wissenschaften, 17, 414-422.

- François, J., Babel, J., de Rouck, A., Dieterle, P., Forni, S., Klein, D., Ricci, A., and Verriest, G. (1963). Les HérédoDégénérescences Chorio-Rétiniennes (Dégénérescences TapétoRétiniennes), 2 vols. Masson, Paris.

- , and Gernet, H. (1965). Diagnostic ultrasonique d'une microphtalmie sans microcornée, avec macrophakie, haute hypermetropie associée à une dégénérescence tapéto-rétinienne, une disposition glaucomateuse et des anomalies dentaires (nouveau syndrome familial). Archives d'Ophtalmologie et Revue Générale d'Ophtalmologie, 25, 105-116.

François, J. (1959). Les Cataractes Congénitales. Masson, Paris.

- (1967). Autosomal chromosome aberrations in ophthalmology. Fournal of the Neurological Sciences, 4, 511-558.

- , Matton-van Leuven, M. Th., and Gombault, Ph. (1970). Uveal coloboma and true Klinefelter syndrome. Fournal of Medical Genetics, 7, 213-223.

Fraser, G. R. (1962). Our genetical 'load'. A review of some aspects of genetical variation. Annals of Human Genetics, 25, 387415.

- and Friedmann, A. I. (1967). The Causes of Blindness in Childhood. A Study of 776 Children with Severe Visual Handicaps. Johns Hopkins, Baltimore.

, - Delhanty, J. D. A., Edwards, J. H., Glen-Bott, A. M., Insley, J., Lele, K. P., Mittwoch, U., and Mutton, D. (1970). Karyotype studies among children with severe visual handicap. British fournal of Ophthalmology, 54, 79-89.

, - Maroteaux, P., Glen-Bott, A. M., and Mittwoch, U. (1969). Dysplasia spondyloepiphysaria congenita and related generalized skeletal dysplasias among children with severe visual handicaps. Archives of Disease in Childhood, 44, 490-498.

Gabilan, J.-C., and Chaussain, J.-L. (1969). L'association hypoglycémie idiopathique et cataracte chez l'enfant. Archives Françaises de Pédiatrie, 26, 633-640.
Gillespie, F. D. (1965). Aniridia, cerebellar ataxia and oligophrenia in siblings. Archives of Ophthalmology, 73, 338-341.

Gitzelmann, R. (1967). Hereditary galactokinase deficiency, a newly recognized cause of juvenile cataracts. Pediatric Research, 1, 14-23.

Hadorn, E. (1955). Letalfaktoren in ihrer Bedeutung für Erbpathologie und Genphysiologie der Entwicklung. Thieme, Stuttgart.

Hemmes, G. D., Nijland, R., and Schappert-Kimmijser, J. (1964). De kans op ontwikkeling van retinoblastoma bij kinderen uit gezinnen waarin deze ziekte is voorgekomen. Nederlandsch Tijdschrift voor Geneeskunde, 108, 1906-1908.

Hermann, P. (1958). Le syndrome microphtalmie-rétinite pigmentaire-glaucome. Archives d'Ophtalmologie et Revue Générale d'Ophtalmologie, 18, 17-24.

Hermanský, F., and Pudlák, P. (1959). Albinism associated with hemorrhagic diathesis and unusual pigmented reticular cells in the bone marrow; report of two cases with histochemical studies. Blood, 14, 162-169.

Hull, D. (1969). Cataracts associated with metabolic disorders in infancy. Proceedings of the Royal Society of Medicine, 62, 694-696.

Ide, C. H., and Webb, R. W. (1969), Hallermann-Streiff syndrome. American fournal of Ophthalmology, 67, 151-153.

Jancke, G. (1950). Cataracta syndermatotica und Ichthyosis congenita. Klinische Monatsblätter für Augenheilkunde, 117, 286-290.

Kjer, P. (1959). Infantile optic atrophy with dominant mode of inheritance. A clinical and genetic study of 19 Danish families. Acta Ophthalmologica, Suppl. 54, 1-147.

Lenz, W. (1955). Recessiv-geschlechtsgebundene Mikrophthalmie mit multiplen Missbildungen. Zeitschrift für Kinderheilkunde, 77, 384-390.

Løken, A. C., Hanssen, O., Halvorsen, S., and Jølster, N. J. (1961). Hereditary renal dysplasia and blindness. Acta Paediatrica, 50, 177-184.

Lowe, C. U., Terrey, M., and MacLachlan, E. A. (1952). Organicaciduria, decreased renal ammonia production, hydrophthalmus and mental retardation. American fournal of Diseases of Children, 83, 164-184.

Lyon, M. F. (1961). Gene action in the X-chromosome of the mouse (Mus Musculus L.). Nature (London), 190, 372-373.

McKusick, V. A. (1966). Heritable Disorders of Connective Tissue, 3rd ed. Mosby, St. Louis.

-, Stauffer, M., Knox, D. L., and Clark, D. B. (1966). Chorioretinopathy with hereditary microcephaly. Archives of Ophthalmology, 75, 597-600.

Nettleship, E. (1912). A pedigree of congenital night-blindness with myopia. Transactions of the Ophthalmological Society of the United Kingdom, 32, 21-45.

O'Connor, C. F., and Crawford, J. D. (1967). Hypoglycemia in infancy. Appraisal of the problem, methods of investigation, possible association of cataracts. Clinical Pediatrics, 6, 94-105.

Pinkerton, O. D. (1958). Cataract associated with congenital ichthyosis. Archives of Ophthalmology, 60, 393-396.

Rieger, H. (1934). Beiträge zur Kenntnis seltene Missbildungen der Iris. II. Über Hypoplasie des Irisvorderblattes mit Veragerung und Entrundung der Pupille. Albrecht v. Graefes Archiv fiur Ophthalmologie, 133, 602-635.

Rose, F. C., Fraser, G. R., Friedmann, A. I., and Kohner, E. M. (1966). The association of juvenile diabetes mellitus and optic atrophy: clinical and genetical aspects. Quarterly fournal of Medicine, 35, 385-405.

Schachenmann, G., Schmid, W., Fraccaro, M., Mannini, A., Tiepolo, L., Perona, G. P., and Sartori, E. (1965). Chromosomes in coloboma and anal atresia. Lancet, 2, 290.

Schmidt, B., Jaeger, W., and Neubauer, H. (1967). Ein Mikrozephalie-Syndrom mit atypischer tapetoretinaler Degeneration bei 3 Geschwistern. Klinische Monatsblätter für Augenheilkunde, 150, 188-196.

Senior, B., Friedmann, A. I., and Braudo, J. L. (1961). Juvenile familial nephropathy with tapetoretinal degeneration. A new oculorenal dystrophy. American fournal of Ophthalmology, 52, 625-633.

Smith, J. L., Cavanaugh, J. J. A., and Stowe, F. C. (1960). Ocular manifestations of the Pierre Robin syndrome. Archives of Ophthalmology, 63, 984-992.

Sorsby, A. (1934). Anophthalmos: an unpublished manuscript by James Briggs giving the first account of the familial occurrence of the condition. British fournal of Ophthalmology, 18, 469-472.

, and Williams, C. E. (1960). Retinal aplasia as a clinical entity. British Medical fournal, 1, 293-297. 
Speakman, J. S., and Crawford, J. S. (1966). Congenital opacities of the cornea. British fournal of Ophthalmology, 50, 68-78.

Steward, J. K., Smith, J. L. S., and Arnold, E. L. (1956). Spontaneous regression of retinoblastoma. British fournal of Ophthalmology, 40, 449-461.

Trevor-Roper, P. D. (1952). Marriage of two complete albinos with normally pigmented offspring. British fournal of Ophthalmology, 36, 107-108.

Usher, C. H. (1921). A pedigree of microphthalmia with myopia and corectopia. British fournal of Ophthalmology, 5, 289-299.

van Canneyt, and Vandemeulebroecke (1936). A propos d'un cas d'anophtalmie bilatérale. Bulletin de la Société Belge d'Ophtalmologie, 73, 17-20.

Vogel, F. (1957). Neue Untersuchungen zur Genetik des Retinoblastoms (Glioma Retinae). Zeitschrift für menschliche Verertungsund Konstitutionslehre, 34, 205-236.
Waardenburg, P. J., and Schappert-Kimmijser, J. (1963). On various recessive biotypes of Leber's congenital amaurosis. Acta Ophthalmologica, 41, 317-320.

Walsh, F. B., and Wegman, M. E. (1937). A pedigree of hereditary cataract, illustrating sex-limited type. Bulletin of the fohns Hopkins Hospital, 61, 125-135.

Warburg, M. (1966). Norrie's disease. A congenital progressive oculo-acoustico-cerebral degeneration. Acta Ophthalmologica, Suppl. 89, 1-147.

Watillon, M., Weekers, R., Marriaux, E., and Joachim, M. (1964). Rétinoblastome héréditaire. Archives d'Ophtalmologie et Revue Générale d'Ophtalmologie, 24, 279-283.

Weyers, H., and Thier, C. J. (1958). Malformations mandibulofaciales et délimitation d'un syndrome oculo-vertébral. fournal de Génétique Humaine, 7, 143-173.

Witkop, C. J., Jr., Nance, W. E., Rawls, R. S., and White, J. G. (1970). Autosomal recessive oculocutaneous albinism in Man; evidence for genetic heterogeneity. American fournal of Human Genetics, 22, 55-74. 